\title{
Patients that refuse blood transfusions: clinical and ethical dilemmas on approaching haemorrhagic shock
}

V. Gonçalves ${ }^{1}$, A. Veiga de Sá ${ }^{1}$, A. Morais ${ }^{1}$, I. Aragao², Z. Moreira², H. Machado 3

Centro Hospitalar do Porto, Department Anaesthisiology, Intensive Care and Emergency, Anaesthesiology Service, Porto, Portugal

1: Anesthesia Resident; 2: Anesthesia Consultant; 3: Head of Anaesthesiology Service

\section{Background}

Treatment of acute blood loss in patients that refuse blood transfusion (BT) represents not only an anaesthetic and clinical challenge but an ethical and sociological problem. Jehovah witnesses (JW) refuse BT based on religious beliefs. In our country, it is common for JW to carry an informed and signed consent in which they state their refusal on red cells (RC), white cells (WC), platelets (P) and fresh frozen plasma (FFP) transfusion.

\section{Case Report}

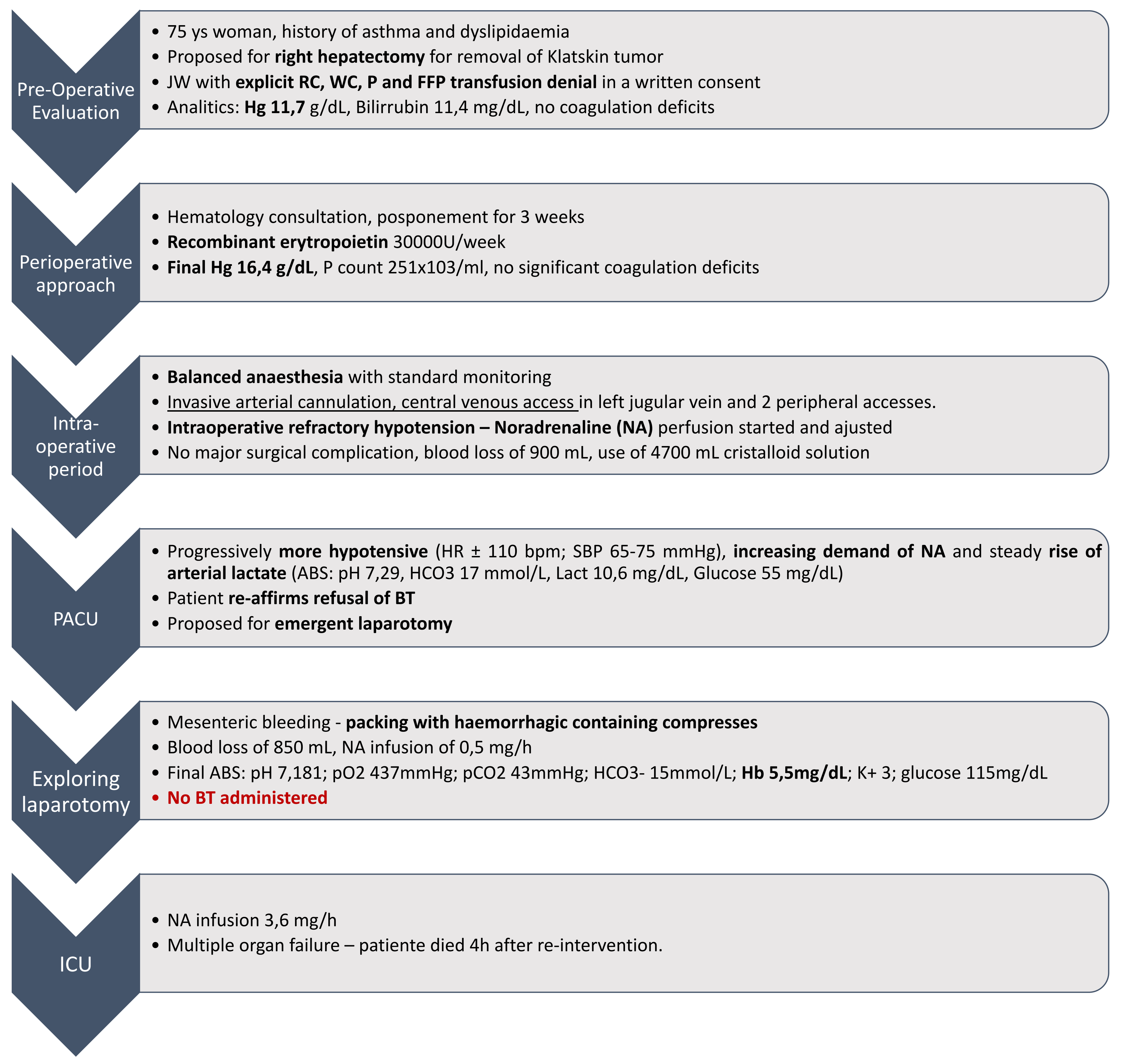

\section{Discussion and Conclusion}

In this case, the team agreed to preserve respect for the patient's autonomy since she had been deemed competent to accept or refuse any proposed treatment, and had been extensively informed about the potential complications of refusal of blood transfusions. However, this refusal may constitute an ethical dilemma for physicians, particularly facing life-threating situations whereas a blood transfusion might save the patient's life and alternative treatments are unproven or unavailable. 